\title{
School Bag Usage, Postural and Behavioral Habits and Its Effect on Back Pain Occurrence Among School Children
}

\author{
Samia Ali El-Nagar ${ }^{1}$, Maha Mohamed Mady ${ }^{2}$ \\ ${ }^{1}$ Community Health Nursing, Faculty of Nursing, Menoufia University, Shebin El-Kom, Egypt \\ ${ }^{2}$ Physical Therapy for Women Health, Teaching Hospital, Shebin El-Kom, Egypt
}

Email address:

Samia.elnagar@yahoo.com (S. A. El-Nagar), Mahamady12@yahoo.com (M. M. Mady)

\section{To cite this article:}

Samia Ali El-Nagar, Maha Mohamed Mady. School Bag Usage, Postural and Behavioral Habits and Its Effect on Back Pain Occurrence Among School Children. American Journal of Nursing Science. Vol. 6, No. 3, 2017, pp. 218-231. doi: 10.11648/j.ajns.20170603.20

Received: March 22, 2017; Accepted: April 1, 2017; Published: April 13, 2017

\begin{abstract}
Back pain is currently growing as a major health problem among school age group children, which can limit or hinder their daily life activities. The aim of the study was to determine the effect of school bag use, postural and behaviors habits on back pain occurrence among school children. Descriptive correlation design was used. This study was conducted at ten governmental preparatory schools from both rural and urban schools in Menouf district, Menoufia Governorate, Egypt. Random sample of 598 preparatory school children including 239 boys and 359 girls aged between 12-15 years of both rural and urban selected schools. Tools: Self-administered structured questionnaire, back pain assessment questionnaire, back pain \& body posture evaluation instrument, behavioral habits questionnaire, school bag use questionnaire, and physiological measurements. The main results showed that $74.1 \%$ of the studied schoolchildren had suffered from back pain. Female students had significant risk of suffering from back pain by five times than male students. Among school children with back pain, 51.3\% had reported moderate pain, the most affected area by pain was shoulder and about one fourth (24.4\%) reported that the pain prevented them from performing daily activities. The mean weight of schoolbag carried by all school children was $7.46+2.62 \mathrm{~kg}$ and the mean school bag weight as \% of body weight was $14.36 \% \pm 4.22$. There was significant relationship between back pain and school bag weight, \% of body weight, method and duration of carriage. Also, there was a significant relationship between back pain and improper sitting posture for writing, using computer, and sitting in classroom. The study was concluded that back pain among studied school children was high and the pain influences activities of daily life in about one fourth of students. Most of school children carry school bags more than the recommended weights of their body weight. It was associated with sex, parents' history of back pain, duration of sedentary activities, improper posture adopted in performing daily activities, weight of schoolbag, method \& duration of carrying schoolbag. Recommendations: The need for developing and implementing of preventative programs in schools about proper postures during daily activities and guidelines for school bag usage.
\end{abstract}

Keywords: Back Pain, School Children, Postural Habits, School Bag Weight, Sedentary Activities

\section{Introduction}

Musculoskeletal health of school age children is a global health problem [1]. There is evidence that the prevalence of musculoskeletal problems in school children and adolescents is increasing [2]. Pain associated with musculoskeletal complaint is a condition where a part of the musculoskeletal system is injured overtime. It not only affects the tendons and the muscles but also the nerves and joints in the neck, upper back, chest, shoulders, arms and hands [3]. Epidemiological data showed that back pain is a significant problem not only in the group of adults but also among children and youth [4]. Besides, the findings of studies revealed that back pain reports in childhood and adolescence are related to back pain in adulthood [5].

Back pain in children and adolescents is reported to be common, increases with age and considered as a growing public health crisis $[6,7]$. For the majority of the children, back pain experiences are mostly non-specific, mild in nature [6]. In addition, it is leading to little effect on health-related quality of life and low associated disability [8]. However, 
epidemiological research showed that back/neck pain may have a negative influence on the daily activities of adolescents as lifting objects, physical activity, and learning concentration [9].

The prevalence rate of back pain among school children ranges from 12 to $92 \%$ depending on the regions. Epidemiological study reported that back pain was experienced by $76.2 \%$ of children and youth aged 10-19 from the area of the Southeast of Poland [6]. In Egypt, a cross-sectional study was conducted among Egyptian school girls aged 11-14 years by [10] showed that the prevalence of back pain was high (45.8). Another study conducted in Nigerian by [5] concluded that back pain prevalence among school children aged 8 to 13 years is high $(73.6 \%)$.

Back pain is not due to a specific single condition, but there are several risk factors that may be associated with the occurrence of nonspecific back pain in children and adolescents including, age, gender [6,7] participation in sports activities for long time [11] time spent per day watching television, using the computer and playing video games [13] Poor life style habits and prolonged static sitting in bad posture [13] psychosocial factors and family history of back pain [14]. Also, carrying heavy school bags is one of the major important causes of back pain among school children [15]. There is ongoing concern regarding the weight of children school bags, improper use and the negative consequences of such heavy loads on the developing spine. There is particular concern for the school children, as the spine is at a critical stage of development in children between $12-14$ years of age [15].

Heavy school bags cause stress on the spine, back and shoulders, resulting in muscular pain, fatigue and strain. Many students carry school bags that exceed 10 percent to 15 percent of their body weight, which puts them at risk for back pain and related disorders. Improper school bag use can also lead to poor posture. Children may be especially at risk for school bag related injuries because they're smaller and may carry loads that are heavier in proportion to their body weight. Carrying school bag increases the risk of back pain and possibly the risk of back pathology. The daily physical stresses associated with carrying school bag cause significant forward lean of the head and trunk. It is assumed that daily intermittent abnormal postural adaptations could result in pain and disability in school going children [16]. Experts recommended that the weight of a school bag must not be more than $10 \%$ of the student's body weight and the weight must be placed on both shoulders [17].

Body postures adopted by school children during activities of daily life such as carrying school bag, sitting to write and use the computer, lifting objects from the floor and sleeping postures are considered by health professionals as the risk factor for the occurrence of back pain [14]. Some studies evaluated the relationship between postural habits when watching television and using the computer and back pain confirmed that back pain is highly prevalent, has a significant impact on late adolescence, and associated with inappropriate home postural habits [18, 19].
Schools are considered to be appropriate places to perform activities that service proper physical and motor development in children, understanding of the relation between back pain and its several contributing factors will allow health care professionals to utilize the resources that are accessible for information, prevention and early detection in school setting [20].

The community health nurse has a vital role in the provision of health services to children and youth in school setting, identifying the major health problems experienced by children, providing preventive and screening services, health education and help with decision-making about health. Health screenings can decrease the negative effects of health problems on education by identifying students with potential health problems early and referring them for treatment as appropriate [21, 22]. Children are the future of the nation and hence, identification of health problems early in life and preventing them from becoming chronic is of greatest importance [16].

\subsection{Significance of the Study}

Children of today are more stressed, weigh more, and are either sedentary or over-involved in physical activities when compared with past generations. All of these factors put stress on the spine and surrounding structures and tighten hips and shoulders, which can adversely influence back comfort [23]. Back pain among school children and adolescents has been growing alarmingly [24]. Epidemiological study reported that the prevalence of back pain among children and youth aged 10-19 was 76.2\% [16]. Although the relationship between the back pain in adolescents and in adults is well recognized and the presence of this disorder in adolescence increases its persistent in adulthood [25] this health problem has been neglected in developing countries, and more research on it is needed [26]

Non-specific back pain, neck pain, shoulder pain and poor posture among school children are topics of increasing significance in the literature and were mostly related to overloaded caused by heavy schoolbags [27]. Adolescent spine is in critical stage of development. Selection of bag with unsafe characteristics, wrong method of carrying it and use of heavy bags by children especially in this sensitive period of vertebral column growth, may cause possible adverse effect on spine, musculoskeletal system, and posture making them prone for development of mobility problems during adulthood ([15]. The prevalence of school children carrying heavy school bag is extremely high [16]. Also, body postures adopted during daily activities a risk factor for the occurrence of back pain. Back pain arising from improper use of the body in activities of daily life develops over several years, starting in the school phase and extending throughout life, and the pain deteriorates to the extent that inactivity has become prevalent in current society [28]. Behaviors during developmental years can influence future health risk in later life; therefore young people are considered an important target group for early detection of health problems [29]. 


\subsection{Aim of the Study}

The aim of this study was to determine the effect of school bag usage, postural and behaviors habits on back pain occurrence among school children.

\subsection{Research Questions}

a What is the occurrence, frequency, affected regions and intensity of back pain among males and females school children?

b Does back pain affect the activities of daily life of school children?

c What is the action taken to alleviate back pain?

$\mathrm{d}$ Is there relationship between back pain and sociodemographic characteristics of school children?

e Is there relationship between back pain and school bag usage (method of carrying, duration of carriage, method of transportation and bag weight)?

$\mathrm{f}$ Is there relationship between back pain and postural habits of school children?

$\mathrm{g}$ Is there relationship between behavior habits and back pain among school children?

$h$ Is there relationship between body mass index and back pain among school children?

\section{Subjects and Methods}

\subsection{Research Design}

Descriptive correlation design was used to achieve the aim of the study.

\subsection{Research Setting}

The study was conducted at ten governmental preparatory schools (six rural and four urban) in Menouf district, Menoufia Governorate, Egypt.

\subsection{Sample}

Random sample of 598 preparatory school children including 239 boys and 359 girls aged between 12-15 years. A multistage random sampling technique was used to select sample. First, Menouf district was chosen randomly from the 9 districts in Menoufia governorate, Egypt. Then random selection of ten governmental schools (six rural and four urban) using simple random technique from a list of preparatory schools which was obtained through Directorate of Education in Menouf district. Then three classes were selected randomly from each school, where one class from each educational grade from first, second and third grade. A systematic random sample was used to select students' from each class. The students' selection was based on the specific criteria which excluded students with major accidental injury, previous surgeries in the back, rheumatoid disease; foot or ankle deformities and child have a chronic or serious illness which requires taking daily medication.

Sample size: It was calculated using the online Epi-info software for sample size calculation according to the following equation: $\mathrm{n}=[\mathrm{DEFF} * \mathrm{~Np}(1-\mathrm{p})] /[(\mathrm{d} 2 / \mathrm{Z} 21-\alpha / 2 *(\mathrm{~N}-$ 1) $\left.+p^{*}(1-p)\right]$.

(1) Population size (total preparatory school children during academic year 2015-2016) about 6050 in the selected schools in Menouf district, Menoufia Governorate, Egypt ( i: e $(\mathrm{N})=6050$

(2) Hypothesizes \% frequency of outcome factor in the population (p): $50 \%+/-5$

(3) Confidence limits as \% of 100 (absolute $+/-\%$ ) (d): $5 \%$

(4) Design effect (for cluster surveys-DEFF): 1

(5) Sample Size (n) for 99\% Confidence Levels was 598 school children.

\subsection{Tools of the Study}

Data was collected through using the following tool

\subsubsection{Self-Administered Structured Questionnaire}

It was designed by the researchers based on review of the related literatures and included the following:

a Socio demographic data: It was included name of student, sex, age, school year, parent's education and place of residence.

b Parents' history of back pain: it was reported by asking students about occurrence of back pain in parents and the response of question in the form of yes or no.

\subsubsection{Back Pain Assessment Questionnaire}

It was developed by the researchers and included questions about:

a Occurrence of back pain: The children were asked to indicate if they had experienced any ache, pain or discomfort during the last month prior to the study, schoolchildren who reported yes to this question complete the remaining part of the pain questionnaire.

b Frequency of the pain: It was reported by children who suffered from back pain. Frequency of back pain was indicated on a 4-point-scale (once a month, once a week, 2-3 times a week, 4 times or more a week).

c Site of the pain: It was assessed through a picture showing four human body regions (neck, shoulders, upper back and lower back). The picture adopted from Papadopoulou et al., [30]. Children who reported pain were asked to mark the pain area in a picture beside the question to help the child to recognize the affected area. Students' response to the question by yes or no.

$\mathrm{d}$ Intensity of the pain: It was assessed by using Numeric Rating Scale [31] for self-report of pain intensity, which consists of a straight horizontal line, numbered at equal intervals from 0 to 10 . The children were asked to draw a cross on the line to indicate the pain level. Pain intensity was indicated on a 4-point-scale no pain (0), mild pain (1-3), moderate pain (4-6), and severe pain (7-10).

e Action taken to alleviate pain: It was assessed by asking students' about action taken to relieve back pain and response in the form of four alternative options (No action, taking analgesics prescribed by a physician, 
analgesics not prescribed by a physician, physiotherapy as massage.

$\mathrm{f}$ Consequence of back pain: Children who reported pain were asked did the pain prevented from performing daily life activities, such as playing, studying and participating in sports.

\subsubsection{Back Pain and Body Posture Evaluation Scale Instrument (Back PEI)}

[32]It was used to assess postural habits during activities of daily life. This instrument included questions about body postures adopted during daily activities such as posture adopted for sleeping; sitting posture adopted when using the computer, in classroom and writing; posture adopted when lifting an object from the floor and carrying school materials. Each question was illustrated with pictures showing participants performing the activities of daily life. Responses of students in the form alternatives and the researchers were asked students to select only one alternative that was considered the proper way to perform each activity; the remaining alternatives were grouped as improper. Photographs were used because they aid school children in the identification of their own posture in the activities of daily life. Furthermore, using one model of the BackPEI for boys and another for girls.

\subsubsection{Behavioral Habits Assessment Questionnaire}

It was developed by researchers and assessed by practice of physical exercise at school or outside, frequency of practice weekly, television, and computer usage. For television and computer use, participants were asked about number of hours spent per day watching television, using the computer in playing games, use the internet, or chat online. The total amount of sitting time per day was assessed by sum of hours spent in different sedentary activities while studying, playing on computer and watching television. It was classified as 5 hours or less per day, 6-7 hours per day, 8 hours or more per day.

\subsubsection{School Bag Use Questionnaire}

It was developed by researchers and included questions about type of school bag, method and duration of carriage, perception of the children regarding schoolbag weight, method of transportation to \& from school and schoolbag weight. The weight of schoolbag including everything in schoolbag on the day of measurement, e.g., water bottle, books, and food was taken for each student using weighing scale with an accuracy of $\pm 0.1 \mathrm{~kg}$. The weight of student was first measured when carrying the schoolbag and then without the schoolbag and the difference between two weights were recorded as the weight of the school bag. To ensure consistency of the procedure, the bag weight measurements were taken on the same day by the same researcher, and the average value out of three measurements was recorded and schoolbag weight was estimated as a percentage of student body weight $(\%$ of $\mathrm{BW})$; it was calculated by dividing the average daily bag weight by the weight of the child and multiplies by 100 .

\subsubsection{Physiological Measurements}

This included height, weight and BMI for each student. Height was recorded to the nearest 0.5 centimeter. Body weight was measured in kilogram using a weighing scale with the student barefoot. Weight was recorded to the nearest 0.1 kilogram and the BMI was estimated by dividing weight in kilogram by squared height in meters [BMI = weight $(\mathrm{kg}) /$ height $\mathrm{m}^{2}$ ].

\subsection{Validity of the Tool}

Validity indicated the degree to which the tool measures what it is expected to measure, therefore, questionnaire content validity was determined by a jury of experts in physiotherapists, pediatric and community health nursing. The necessary modifications were carried out according to the panel judgment on clarity of the sentences and appropriateness of the contents.

\subsection{Reliability of the Tool}

Reliability of the tool was measured by the researchers for testing the internal consistency of the tools. Reliability of the tool was confirmed through test re-test method with two weeks interval on a group of students not participating in the study. The reliability of data were analyzed using the kappa coefficient which ranges from 0.78 for back pain and body posture evaluation instrument, 0.83 for behavioral habits assessment questionnaire, 0.87 for school bag use questionnaire and 0.92 for back pain assessment questionnaire. This indicates good reliability of the study tools for conducting this research study.

\subsection{A Pilot Study}

It was conducted on $10 \%$ of participants to estimate clarity, applicability of the tool, and the needed time to fill questionnaire. Based on the results of the pilot study, modifications and clarifications of some questions were done. The pilot sample was not included in the total sample of the research work to ensure stability of the answers.

\subsection{Ethical Considerations}

Researchers followed all the ethical issues in conducting the research. All selected children who were willing to participate in the study and fulfilling the criteria were given a written consent form to be approved by their parents, which includes simple description about aim of the study and its significance. Informed consent was obtained from both the participants and their parents before participation in the study. The participants were informed that participation in this study is voluntary; they can withdraw at any time during the study without giving reasons. The researchers were explained the aim of the study to all students in the study sample. They reassured that any obtained information would be strictly confidential. 


\subsection{Data Collection Procedure}

a This study was conducted during the period starting from November 2015 to the end of April 2016.

b Necessary approval was obtained from the director of directorate of education and director of each selected school after issuing letters to them from the Faculty of Nursing, Menoufia University explaining the aim of the study and method of data collection to obtain permission for conducting the study.

c After obtaining approval and written informed consent from school children and their parents to conduct the study, the researchers were initiated data collection from students who fulfilled the selection criteria two days per week for six months through using self-administered structured questionnaires about socio-demographic data, family history of back pain. Also, back pain questionnaire including occurrence, frequency, sites, intensity, action taken to alleviate pain and consequence on activity of daily life, characteristics of school bag use, postural behaviors and measurements of students' height, body weight, and school bag weight.

d Questionnaire was completed during school time under supervision of the researchers. Before distributing the questionnaire, the researchers were explained purpose of the study to the selected participants in each class in the selected schools and gave them instructions to fill it. Then, the students answered the questionnaires individually and the researchers were present in the classroom during data collection to clarify and simplify any question for the students.

e Anthropometric measurements including students' height, body weight, and BMI was taken for each student in the study. Additionally, schoolbag weight was measured.

f Data collection was conducted on an unscheduled day so that students could not change their school bag weight.

g The average time taken for completing questionnaires was around 30- 35 minutes.

Statistical Analysis: Data was entered and analyzed by using SPSS (Statistical Package for Social Science) version 22. Graphics were done using Excel program. Quantitative data were presented by mean $(\mathrm{X})$ and \pm standard deviation (SD). Qualitative data were presented in the form of frequency distribution tables, number and percentage. In order to suggest some risk factors for back pain among Egyptian school children, and accordingly help in formulating and developing hypotheses about back pain etiologies, data from this entire population (school children) were used to compare disease frequency between different groups (school children who have back pain, and those who had not back pain), during the same period of time. Although using OR and confidence interval in descriptive correlational and cross section studies is controversy (Newcombe, 2012) [50], we used it as a measure of effect size to help in determining which are the higher risk factors that can be suggested for developing hypothesis related to the etiology of back pain among studied school children. Accordingly, Odds ratio with $95 \%$ CI was used as a measure of relationship between back pain and some demographic characteristics, school bag use, postural and behavioral habits of school children. In order to explore the relationship between back pain of school children and the following quantitative variables [age, school bag weight $(\mathrm{kg}), \%$ of school bag weight to student weight, height $(\mathrm{cm})$, weight $(\mathrm{kg})$, body mass index (BMI) $(\mathrm{kg} / \mathrm{m} 2)]$, we first confirmed that these variables were normally distributed by histogram and Kolmogorov as a confirmatory test, then the SPSS's independent-sample $\mathrm{T}$ test was used for comparison between two means. Qualitative data were analyzed by chi-square $(\chi 2)$ test. No correlation analysis was used in this research. Level of significance was set as $\mathrm{P}$ value $<0.05$ for all significant tests.

\section{Results}

Table 1: Shows that the mean age of school children in the studied sample was $13.64 \pm 0.74$ years and more than half of them were females (59.8\%). Regarding parents education and residence, more than half of students' fathers and mothers had secondary and university education and about two thirds (64\%) of school children were from rural area,. Concerning parents' history of back pain, approximately three fourths of school children $(71.9 \%)$ had parents' history of back pain.

Table 1. Distribution of socio-demographic characteristics of school children $(n=598)$.

\begin{tabular}{lll}
\hline Socio-demographic characteristics & No. & $\%$ \\
\hline Age (years) & & \\
- Mean \pm SD & $13.64 \pm 0.74$ & \\
Sex & & \\
- Male & 239 & 40.0 \\
- Female & 359 & 60.0 \\
Fathers' Education & & \\
- Illiterate & 115 & 19.2 \\
- Basic education & 170 & 28.5 \\
- Secondary & 131 & 21.9 \\
- University & 182 & 30.4 \\
Mothers' education & & \\
- Illiterate & 186 & 31.1 \\
- Basic education & 84 & 14.0 \\
- Secondary & 211 & 35.3 \\
- University & 117 & 19.6 \\
Residence & & \\
- Rural & 383 & 64.0 \\
- Urban & 215 & 36.0 \\
Parents' history of back pain & & 71.9 \\
- Yes & 430 & 18.1 \\
- No & 108 & 10.0 \\
- Don't know & 60 & \\
\hline
\end{tabular}

Figure 1: Shows that about three fourths (74.1\%) of the studied school children had suffered from back pain in the past month prior to the study. The occurrence of back pain among females was significant higher $(86.6 \%)$ than among males $(55.2 \%)$. The difference between males and females was statistically significant $\left(\mathrm{X}^{2}=73.67, \mathrm{P}=0.000\right)$. 


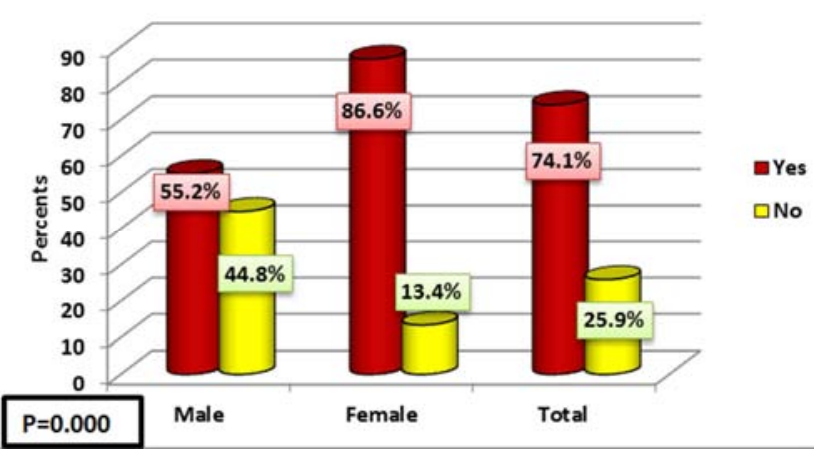

Figure 1. Frequency of back pain among school children distributed by gender.

Table 2: Shows that $51.3 \%$ of school children with back pain had reported moderate pain and more than one third $(35.2 \%)$ had mild pain while $13.5 \%$ had severe pain. The difference between males and females was not statistically significant $(\mathrm{P}>0.05)$. Regarding frequency of pain, among school children with back pain, more than one third of school children $(37.7 \%)$ reported feeling back pain two and three times per week, $35.2 \%$ one-time per week and only $10.8 \%$ four times or more per week. The difference between males and females was statistically significant $(\mathrm{P}=0.00)$. Concerning impairment in activities of daily life, about one fourth $(24.4 \%)$ of school children with back pain reported that the pain prevented them from performing activities of daily life such as studying, participating in leisure activities, and playing. The difference between males and females was not statistically significant $(\mathrm{P}>0.05)$. Also, this table shows that $71.3 \%$ of school children who reported back pain did not take any action for alleviating back pain, $14.4 \%$ alleviate pain with analgesic not prescribed by doctor while $10.2 \%$ used analgesic prescribed by doctor and only $4.1 \%$ used different forms of physiotherapy such as massage to eliminate pain. The difference between males and females was not statistically significant $(\mathrm{P}=0.00)$.

Table 2. Distribution of back pain intensity, frequency and impairment of performing daily activities in schoolchildren who reported pain by sex (443).

\begin{tabular}{|c|c|c|c|c|c|c|c|}
\hline \multirow{2}{*}{ Intensity\& frequency of back pain } & \multicolumn{2}{|c|}{ Male (132) } & \multicolumn{2}{|c|}{ Female (311) } & \multicolumn{2}{|c|}{ Total } & \multirow{2}{*}{ P Value } \\
\hline & No. & $\%$ & No. & $\%$ & No. & $\%$ & \\
\hline \multicolumn{8}{|l|}{ Intensity of back pain } \\
\hline Mild & 48 & 36.4 & 108 & 34.7 & 156 & 35.2 & \\
\hline Moderate & 60 & 45.5 & 167 & 53.7 & 227 & 51.3 & $X^{2}=4.28$ \\
\hline Severe & 24 & 18.1 & 36 & 11.6 & 60 & 13.5 & $P=0.117$ \\
\hline \multicolumn{8}{|l|}{ Frequency of back pain } \\
\hline Once /month & 36 & 27.3 & 36 & 11.6 & 72 & 16.3 & \\
\hline 2-3 times /week & 36 & 27.2 & 131 & 42.1 & 167 & 37.7 & $\mathrm{P}=0.000^{*}$ \\
\hline 4 times or more /week & 12 & 9.1 & 36 & 11.6 & 48 & 10.8 & \\
\hline \multicolumn{8}{|l|}{ Impairment in performing daily activities } \\
\hline Yes & 26 & 19.7 & 82 & 26.4 & 108 & 24.4 & $\mathrm{X}^{2}=2.24$ \\
\hline No & 106 & 80.3 & 229 & 73.6 & 335 & 75.6 & $\mathrm{P}=0.135$ \\
\hline \multicolumn{8}{|l|}{ Action taken to alleviate pain } \\
\hline - No action & 68 & 51.5 & 248 & 79.7 & 316 & 71.3 & \\
\hline - Physiotherapy & 12 & 9.1 & 6 & 1.9 & 18 & 4.1 & \\
\hline
\end{tabular}

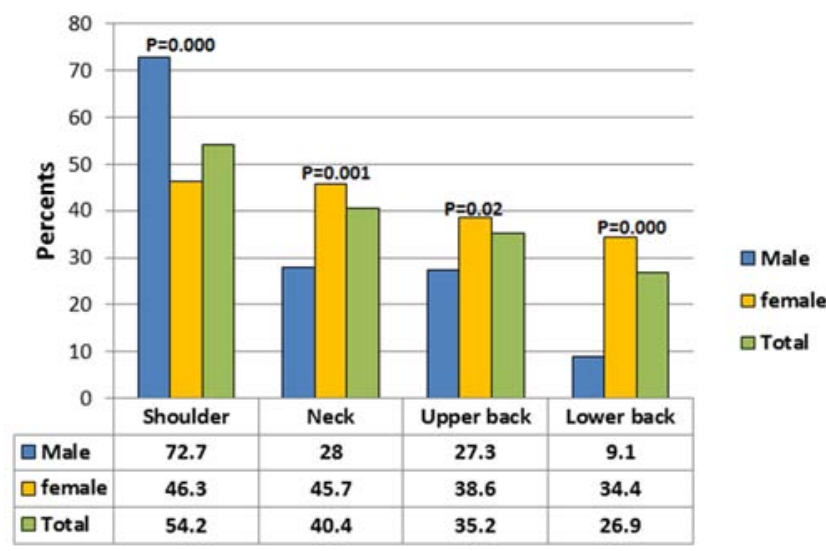

Figure 2. Distribution of affected regions of the back with pain according to $\operatorname{sex}(n=443)$.

Figure 2: Among school children with back pain, more than half $(54.2 \%)$ of students reported pain in the shoulder region, followed by neck (40.4\%), upper back (35.2\%) and lower back $(26.9 \%)$. The difference between males and females was statistically significant $(\mathrm{P}=0.000,0.001,0.02$, $0.000)$ respectively).

Table 3: Shows that age, fathers' education, and residence were not significant associated with occurrence of back pain among studied school children $(\mathrm{P}>0.05)$. However, it reveals that gender, mothers' education, and parents history of back pain had significant associated with occurrence of back pain among school children ( $\mathrm{p}=0.000,0.04 \& 0.000$, respectively). Females students had a significant risk of suffering from back pain by five times than males students' $(\mathrm{OR}=5.2)$. Students having mothers with basic education are 1.2 times more likely to suffer from back pain than students whose university mothers. In addition, students with positive parents' history of back pain are four times more likely to suffer from back pain than students with negative parents' history of back pain $(\mathrm{OR}=4.0)$.

Table 4: Shows that type of school bag and method of transportation to and from school had no associated with 
occurrence of back pain among studied students $(\mathrm{P}>0.05)$. However, it seems that duration of carriage school bag, method of carrying school bag, \% of school bag weight to student weight, feeling school bag heavy had a significant associated with occurrence of back pain ( $\mathrm{p}=0.000,0.0 .000$, $0.001 \& 0.000$ respectively). Students who are carrying school bags for 20 -30 minutes or more per day were more likely to suffer from back pain by about three times than students who are carrying school bags for $<10$ minutes. Carrying school bag on one shoulder or by one hand increases the risk of suffering from back pain by 3.6 times (OR 95\% CI $=2.5-5.3$ ) than a students' carrying school bags on both shoulders. School children who carrying school bags between $10.1 \%-15 \%$ and $>15 \%$ of their body weight had more likely to suffer from back pain complain by about 2.6 times and 6.1 times respectively than those carrying school bags $\leq 10 \%$ of their body weight. Additionally, students who reported that their school bags heavy were 2.4 times more likely to suffer from back pain than school children who were not having this feeling $(\mathrm{OR}=2.4)$.

Table 3. Effect of socio-demographic characteristics of school children on occurrence of back pain $(n=598)$.

\begin{tabular}{|c|c|c|c|c|c|c|}
\hline \multirow{3}{*}{$\begin{array}{l}\text { Socio-demographic } \\
\text { characteristics }\end{array}$} & \multicolumn{5}{|c|}{ Occurrence of back pain } & \multirow{3}{*}{$P$ value } \\
\hline & \multicolumn{2}{|l|}{ Yes (443) } & \multicolumn{2}{|l|}{ No (155) } & \multirow[t]{2}{*}{ OR $(95 \% \mathrm{CI})$} & \\
\hline & No. & $\%$ & No. & $\%$ & & \\
\hline Age (years) & \multirow{3}{*}{\multicolumn{2}{|c|}{$13.69 \pm 0.75$}} & \multirow{3}{*}{\multicolumn{2}{|c|}{$13.57 \pm 0.68$}} & \multirow{3}{*}{$13.66 \pm 0.74$} & \multirow{3}{*}{$\begin{array}{l}\mathrm{t}=1.78 \\
\mathrm{P}=0.096 \mathrm{NS}\end{array}$} \\
\hline Mean \pm SD & & & & & & \\
\hline Sex & & & & & & \\
\hline - Male & 132 & 55.2 & 107 & 44.8 & \multirow{2}{*}{ OR (female student) $5.2(3.5-7.8)$} & \multirow{3}{*}{$\begin{array}{l}X^{2}=73.67 \\
P=0.000 * H S\end{array}$} \\
\hline - Female & 311 & 86.6 & 48 & 13.4 & & \\
\hline Fathers' education & & & & & & \\
\hline - Illiterate & 79 & 68.7 & 36 & 31.3 & 1 (reference) & \multirow{4}{*}{$\begin{array}{l}X^{2}=6.04 \\
P=0.11 \\
N S\end{array}$} \\
\hline - Basic education & 134 & 78.8 & 36 & 21.2 & 1.7 & \\
\hline - Secondary & 102 & 77.9 & 29 & 22.1 & 1.6 & \\
\hline - University & 128 & 70.3 & 54 & 29.7 & 1.1 & \\
\hline \multicolumn{6}{|l|}{ Mothers' education } & \multirow{4}{*}{$\begin{array}{l}X^{2}=4.10 \\
P=0.04 \text { Sig. }\end{array}$} \\
\hline - Illiterate & 144 & 77.4 & 42 & 22.6 & 1 (reference) & \\
\hline - Basic education & 68 & 81.0 & 16 & 19.0 & 1.2 & \\
\hline - University & 81 & 69.2 & 36 & 30.8 & 0.6 & \\
\hline \multicolumn{6}{|l|}{ Residence } & \multirow{4}{*}{$\begin{array}{l}X^{2}=0.69 \\
P=0.41 \mathrm{NS}\end{array}$} \\
\hline - Rural & 288 & 75.2 & 95 & 24.8 & $\mathrm{OR}=1.2(0.8-1.7)$ & \\
\hline - Urban & 155 & 72.1 & 60 & 27.9 & & \\
\hline Parents' history of ba & & & & & & \\
\hline No & 60 & 55.6 & 48 & 44.4 & 1 (reference) & \multirow{3}{*}{$\begin{array}{l}X^{2}=75.41 \\
P=0.000 * H S\end{array}$} \\
\hline Yes & 359 & 83.5 & 71 & 16.5 & 4.0 & \\
\hline Don't know & 24 & 40.0 & 36 & 60.0 & 0.5 & \\
\hline
\end{tabular}

HS $=$ High significant, NS = not significant, Sig.= Significant.

OR $(95 \% \mathrm{CI})=$ Odd's Ratio $(95 \%$ confidence Interval $)$

Table 4. Effect of school bag characteristics on occurrence of back pain among schoolchildren ( $n=598)$.

\begin{tabular}{|c|c|c|c|c|c|c|}
\hline \multirow{3}{*}{ Characteristics of school bag } & \multicolumn{5}{|c|}{ Occurrence of back pain } & \multirow{3}{*}{$P$ value } \\
\hline & \multicolumn{2}{|c|}{ Yes (443) } & \multicolumn{2}{|c|}{ No (155) } & \multirow[t]{2}{*}{ OR $(95 \% C I)$} & \\
\hline & No. & $\%$ & No. & $\%$ & & \\
\hline \multicolumn{7}{|l|}{ Type of school bag } \\
\hline One strap & 166 & 78.7 & 45 & 21.3 & 1 (reference) & $\mathrm{X}^{2}=4.38$ \\
\hline Two strap & 232 & 70.7 & 96 & 29.3 & 0.66 & $\mathrm{P}=0.112$ \\
\hline Others & 45 & 76.3 & 14 & 23.7 & 0.87 & NS \\
\hline \multicolumn{7}{|l|}{ Duration of carriage school bag } \\
\hline$<10$ minute & 66 & 60.0 & 44 & 40.0 & 1 (reference) & \multirow{4}{*}{$\begin{array}{l}\mathrm{X}^{2}=28.05 \\
\mathrm{P}=0.000 *\end{array}$} \\
\hline $10-20$ minute & 91 & 65.5 & 48 & 34.5 & 1.3 & \\
\hline 20-30 minute & 162 & 81.4 & 37 & 18.6 & 2.9 & \\
\hline More than 30 minute & 124 & 82.7 & 26 & 17.3 & 3.2 & \\
\hline \multicolumn{7}{|l|}{ Method of carrying school bag } \\
\hline Both shoulder & 101 & 55.8 & 80 & 44.2 & \multirow{2}{*}{$3.6(2.4-5.3)$} & \multirow{3}{*}{$\begin{array}{l}X^{2}=45.16 \\
P=0.000^{*}\end{array}$} \\
\hline On one shoulder or one hand & 342 & 82.0 & 75 & 18 & & \\
\hline \multicolumn{6}{|l|}{$\%$ of school bag weight to student weight } & \\
\hline $10.1-15 \%$ & 109 & 73.6 & 39 & 26.4 & 2.6 & \multirow{2}{*}{$\begin{array}{l}X^{2}=65.97 \\
P=0.000 *\end{array}$} \\
\hline$>15 \%$ & 250 & 86.8 & 38 & 13.2 & 6.1 & \\
\hline \multicolumn{7}{|l|}{ Feeling school bag heavy } \\
\hline Heavy & 407 & 76.1 & 128 & 23.9 & \multirow{2}{*}{$2.4(1.4-4.1)$} & $X^{2}=10.52$ \\
\hline Not heavy & 36 & 57.1 & 27 & 42.9 & & $\mathrm{P}=0.001^{*}$ \\
\hline
\end{tabular}




\begin{tabular}{|c|c|c|c|c|c|c|}
\hline \multirow{3}{*}{ Characteristics of school bag } & \multicolumn{5}{|c|}{ Occurrence of back pain } & \multirow{3}{*}{$P$ value } \\
\hline & \multicolumn{2}{|c|}{ Yes (443) } & \multicolumn{2}{|c|}{ No (155) } & \multirow[t]{2}{*}{ OR $(95 \% \mathrm{CI})$} & \\
\hline & No. & $\%$ & No. & $\%$ & & \\
\hline \multicolumn{7}{|l|}{ Transportation to \& from school } \\
\hline Bus/ car & 24 & 66.7 & 12 & 33.3 & 1 (reference) & \multirow{3}{*}{$\begin{array}{l}\mathrm{X}^{2}=0.04 \\
\mathrm{P}=0.82 \mathrm{~N}\end{array}$} \\
\hline Bike & 58 & 82.9 & 12 & 17.1 & 2.4 & \\
\hline Walking & 361 & 73.4 & 131 & 26.6 & 1.3 & \\
\hline
\end{tabular}

Table 5: Reveals that posture adopted for sleeping and watching television had no significant associated with back pain occurrence among studied school children $(\mathrm{P}>0.05)$. However, it reveals that sitting posture for writing was significant associated with occurrence of back pain among school children $(\mathrm{P}=0.001)$. Students who stayed in sitting posture for long periods during the day in an inappropriate posture (forward trunk flexion, lack of back and a forearm support) had a higher significant percentage of back pain complain $(76.8 \%)$ than those who adopted proper sitting posture for writing $(61.8 \%)$. The odds of proper setting posture for writing in school is half the odds of the improper setting $(\mathrm{OR}=0.5$ (0.3-0.8). Also, sitting posture in classroom was significant associated with the occurrence of back pain among school children $(\mathrm{P}=0.000)$. School children who adopted improper posture in the classroom (back and feet not supported) had a higher significant percentage of back pain (82\%) compared with $45.8 \%$ of students who adopted proper posture (back and feet supported). Furthermore, posture adopted for picking up objects from the floor was significant relationship with occurrence of back pain $(\mathrm{P}=0.000)$. School children who reported picking up objects from the floor with improper posture (trunk flexion without bending the knees) had more occurrence of back pain $(79.5 \%)$ compared to $54.3 \%$ of students who adopted proper posture (bending the knees, keeping the back straight).

Table 6: Regarding behavioral habits, this shows that physical exercise practice and frequency of practice weekly had no associated with back pain occurrence among school children $(\mathrm{P}>0.05)$. However, it reveals that duration /day spent in sedentary activities such as studying, and watching television was associated with occurrence of back pain ( $\mathrm{P}$ $=0.000$ ). Students who spent eight or more hours per day in sedentary activities had approximately three times more likely to suffer from back pain than those spent five hours or less per day.

Table 5. Effect of postural habits of school children on occurrence of back pain ( $n=598)$.

\begin{tabular}{|c|c|c|c|c|c|c|}
\hline \multirow{3}{*}{ Postural habits } & \multicolumn{5}{|c|}{ Occurrence of back pain } & \multirow{3}{*}{$P$ value } \\
\hline & \multicolumn{2}{|c|}{ Yes (443) } & \multicolumn{2}{|c|}{ No (155) } & \multirow[t]{2}{*}{ OR $(95 \% \mathrm{CI})$} & \\
\hline & No. & $\%$ & No. & $\%$ & & \\
\hline \multicolumn{7}{|l|}{ Postural habits } \\
\hline Sleeping posture & & & & & \multirow{3}{*}{$0.74(0.51-1.1)$} & $X^{2}=2.60$ \\
\hline - Proper & 173 & 70.6 & 72 & 29.4 & & $\mathrm{P}=0.107$ \\
\hline - Improper & 270 & 76.5 & 83 & 23.5 & & NS \\
\hline \multicolumn{7}{|l|}{ Sitting posture in classroom } \\
\hline - Proper & 60 & 45.8 & 71 & 54.2 & \multirow{2}{*}{$0.19(0.12-0.28)$} & $X^{2}=69.85$ \\
\hline - Improper & 383 & 82.0 & 84 & 18.0 & & $\mathrm{P}=0.000 * \mathrm{HS}$ \\
\hline \multicolumn{5}{|l|}{ Sitting posture for watching television } & \multicolumn{2}{|l|}{$0.72(0.5-1.1)$} \\
\hline - Proper & 139 & 69.8 & 60 & 30.2 & & $X^{2}=2.78$ \\
\hline - Improper & 304 & 76.2 & 95 & 23.8 & & $\mathrm{P}=0.095 \mathrm{NS}$ \\
\hline \multicolumn{7}{|l|}{ Sitting posture for using computer } \\
\hline - Proper & 121 & 55.5 & 97 & 44.5 & \multirow{2}{*}{$0.23(0.15-0.33)$} & $X^{2}=61.65$ \\
\hline - Improper & 322 & 84.7 & 58 & 15.3 & & $\mathrm{P}=0.000 * \mathrm{HS}$ \\
\hline \multicolumn{7}{|l|}{ Sitting posture for writing } \\
\hline - Proper & 68 & 61.8 & 42 & 38.2 & \multirow{3}{*}{$0.5(0.3-0.8)$} & $\mathrm{X}^{2}=10.56$ \\
\hline - Improper & 375 & 76.8 & 113 & 23.2 & & $\mathrm{P}=0.001 * \mathrm{HS}$ \\
\hline \multicolumn{6}{|l|}{ Posture adopt to pick up object from floor } & \\
\hline -Proper & 70 & 54.3 & 59 & 45.7 & & $X^{2}=33.63$ \\
\hline -Improper & 373 & 79.5 & 96 & 20.5 & $0.3(0.2-0.5)$ & $\mathrm{P}=0.000 * \mathrm{HS}$ \\
\hline
\end{tabular}

Table 6. Effect of behavioral habits on occurrence of back pain among school children ( $n=598)$.

\begin{tabular}{|c|c|c|c|c|c|c|}
\hline \multirow{3}{*}{ Behavioral habits } & \multicolumn{5}{|c|}{ Occurrence of back pain } & \multirow{3}{*}{$P$ value } \\
\hline & \multicolumn{2}{|c|}{ Yes (443) } & \multicolumn{2}{|c|}{ No (155) } & \multirow[t]{2}{*}{ OR (95\% CI) } & \\
\hline & No. & $\%$ & No. & $\%$ & & \\
\hline \multicolumn{7}{|l|}{ Behavioral habits } \\
\hline $\begin{array}{l}\text { Practice of physical exercise regularly } \\
\text { - Yes } \\
\text { - No }\end{array}$ & $\begin{array}{l}252 \\
191\end{array}$ & $\begin{array}{l}71.8 \\
77.3\end{array}$ & $\begin{array}{l}99 \\
55\end{array}$ & $\begin{array}{l}28.2 \\
27.7\end{array}$ & \multirow[t]{2}{*}{$0.7\left(\begin{array}{lll}0.5 & 1.1\end{array}\right)$} & \multirow[t]{2}{*}{$\begin{array}{l}X^{2}=2.31 \\
P=0.12 \mathrm{NS}\end{array}$} \\
\hline Frequency of e exercise/week & & & & & & \\
\hline - No practice & 191 & 77.3 & 55 & 22.7 & 1 (reference) & $\mathrm{X}^{2}=3.14$ \\
\hline
\end{tabular}




\begin{tabular}{|c|c|c|c|c|c|c|}
\hline \multirow{3}{*}{ Behavioral habits } & \multicolumn{5}{|c|}{ Occurrence of back pain } & \multirow{3}{*}{$P$ value } \\
\hline & \multicolumn{2}{|c|}{ Yes (443) } & \multicolumn{2}{|c|}{ No (155) } & \multirow[t]{2}{*}{ OR (95\% CI) } & \\
\hline & No. & $\%$ & No. & $\%$ & & \\
\hline - 1-2 days per week & 120 & 73.2 & 44 & 26.8 & 0.78 & \multirow[t]{4}{*}{$\mathrm{P}=0.070 \mathrm{NS}$} \\
\hline - 3-4 days per week & 84 & 72.4 & 32 & 27.6 & 0.76 & \\
\hline - 5 days or more per week & 48 & 67.6 & 23 & 32.4 & 0.60 & \\
\hline Duration of sedentary acti & & & & & & \\
\hline-5 hours or less & 85 & 60.7 & 55 & 39.3 & 1 (reference) & \multirow{3}{*}{$\begin{array}{l}X^{2}=25.19 \\
P=0.000 * H S\end{array}$} \\
\hline - 6-7 hours & 82 & 68.3 & 38 & 31.7 & 1.4 & \\
\hline-8 or more hours & 276 & 81.7 & 62 & 18.3 & 2.9 & \\
\hline
\end{tabular}

Table 7. Mean of school bag weight, \% of student weight and BMI by occurrence of back pain among school children (598).

\begin{tabular}{lllll}
\hline \multirow{2}{*}{ Measurements } & \multicolumn{2}{l}{ Occurrence of back pain } & \multirow{2}{*}{ Total } & \multirow{2}{*}{ P Value } \\
\cline { 2 - 4 } & Yes & No & Mean+ SD & \\
\cline { 2 - 4 } & Mean + SD & Mean + SD & $7.46+2.62$ & $\mathrm{t}=7.7, \mathrm{P}=0.000^{*}$ \\
School bag weight $(\mathrm{kg})$ & $7.93+2.67$ & 11.1 .95 & $\mathrm{t}=9.33, \mathrm{P}=0.000^{*}$ \\
\% of school bag weight to student weight & $15.25+4.26$ & $151.48+4.18$ & $152.07+4.69$ & $\mathrm{t}=1.81, \mathrm{p}=0.070$ \\
Height $(\mathrm{cm})$ & $152.27+4.84$ & $50.98+6.73$ & $51.54+7.59$ & $\mathrm{t}=1.08, \mathrm{p}=0.283$ \\
Weight $(\mathrm{kg})$ & $51.74+7.87$ & $22.17+2.02$ & $22.58+2.66$ & $\mathrm{t}=1.15, \mathrm{p}=0.178$ \\
Body mass index $(\mathrm{BMI})\left(\mathrm{kg} / \mathrm{m}^{2}\right)$ & $22.45+2.85$ & &
\end{tabular}

Table 7: Reveals the mean weight of school bag carried by all school children was $7.46+2.62 \mathrm{~kg}$. Among schoolchildren complaining of back pain, the mean school bag weight was significant higher $7.93+2.76 \mathrm{~kg}$ compared to $6.12+1.951 \mathrm{~kg}$ carried by schoolchildren not complaining of back pain $((\mathrm{P}=0.000)$. Also, the mean school bag weight as a percentage of body weight ( $\%$ of $\mathrm{BW}$ ) carried by school children in the studied sample was $14.36 \% \pm 4.22$. Among schoolchildren complaining of back pain, the mean school bag weight as a percentage of body weight was significant higher $(15.25 \pm 4.26$ compared to $11.81 \pm 2.84$ among school children not complaining of back pain $(p=0.000)$. On the other hand, the same table shows that there was no significant relationship between weight, height and body mass index of school children and back pain $(\mathrm{P}>0.05)$.

\section{Discussion}

Back pain in children and adolescents is reported to be common, and considered as a growing public health crisis [7]. The present study revealed that about three fourths of school children in the studied sample had suffered from back pain in the past month prior to the study. This finding was in line with [6] who revealed that the prevalence of back pain in children and youth aged10-19 years living in area of the southeast Poland was seventy six percent. Also, similar to [33] who assessed prevalence of back pain among school students aged 12 to 18 years in Dubai, United Arab Emirates. They showed that about two thirds of the studied students reported back pain. However, the result of the present study was higher than that the results of [10] who conducted a study among Egyptian school girls aged from 11-14 years showed that less than half of girls suffered from back pain. Another study conducted in India by [14] they showed that the prevalence of back pain in the last three months among school children aged 11-16 years was fifty five percent. The difference in the percentage value of back pain may be due to difference in age group, gender, sample size, recall period (some studies used one-month, two-month or three month recall period).

Regarding intensity of pain, the present study revealed that among school children with back pain about half had reported moderate pain, more than one third had mild pain while only thirteen percent had severe pain. This result was in accordance with study conducted in southern Brazil among school students by [35] they showed that more than half of students affected by pain reported moderate pain, more than one third mild pain and only $5.9 \%$ had severe pain. On the contrary, a study by [6] showed that mild pain was prevailing which reported by $44.7 \%$ of all children and youth aged 10 19 and nearly every fourth subject reported having experienced strong pain. The difference between the result of the present study and the other studies may be related to variation in age groups, scale used to estimate pain intensity and the last study estimate the proportion of mild, moderate and severe pain from all studied sample.

Concerning frequency of pain, the present study revealed that among school children with back pain, about three fourths of school children reported feeling back pain one time per week or two and three times per week, and only about ten percent four times or more per week and the difference between males and females was statistically significant. This finding was supported by [35] who estimated back pain prevalence among school students in Brazil. They found that the most of the students responded that the pain frequency was one time per week, or between two and three times per week, and only about seven percent more than four times per week. On the contrary, other studies conducted by $[14,36]$ they reported that most of school children feeling back pain only once in the last three months or once a month. This difference may be due to variability in socio-demographic characteristics, recall period and different point Likert scale.

The present result showed that the most affected area by pain was shoulder as reported by more than half of school children followed by forty percent in neck, more than one 
third in upper back and more than one fourth in lower back, the difference between males and females was significant. This finding was in agreement with [30] who found half of students reported pain in their shoulder followed by more than one third in upper back, one fourth in their neck and one fifth in lower back. Also, Ibrahim et al. [37] they found back pain in about two thirds, shoulder pain in more than half and neck pain in about half. Another study by [38] found majority of pupils reported pain especially in the shoulders, followed by upper back, lower back and neck. In Egypt, a study conducted among elementary school children in Assiut city by [39] found two thirds of student had low back pain followed by shoulder pain.

Regarding impairment in daily activities, the present result showed that about one fourth of school children suffered from pain reported that the pain prevented them from performing daily activities such as studying, participating in leisure activities and playing. The difference between males and females was not statistically significant. Similarly, Fonseca et al. [35] who revealed that more than one fifth of students affected by back pain indicated that the pain prevented them from performing activities of daily living. Likewise, Wirth et al. [4] who assessed spinal pain characteristics of adolescent. They showed that the majority of subjects reported that back pain did not result in any consequences. Nevertheless, more than one fourth of adolescents identified that they changed something in their daily lives due to their back pain, including taking pills, reducing their daily activities, or seeing a doctor. Also, similar to the result of [40] who reported that the prevalence of spinal pain limits the ability of youths aged 13-19 year to start everyday activities, including activities related to functioning in school and forces youths to seek the help of specialists.

Concerning action taken to alleviate pain, the current study showed that the majority of school children who reported back pain did not take any action for alleviating back pain, about fourteen percent alleviate pain with analgesic not prescribed by doctor while ten percent used analgesic prescribed by doctor and only four percent used different forms of physiotherapy such as massage to eliminate pain. The difference between males and females was statistically significant $(\mathrm{P}=0.000)$. This result was in line with [6] who reported that over three fourths of the respondents do not take any actions to relieve back pain and a significant number of students in all age groups alleviate pain with over-the-counter medicines. Similarly, a study conducted in Denmark by [41] who studied prevalence and consequence of back pain from childhood to adolescence. They found that care-seeking for back pain was uncommon in children. Likewise, a study among students in Brazil by [42] stated that only five percent of students who showed symptoms of pain had previously made medical consultation.

Relation between back pain and socio- demographic characteristics, the present result revealed that age, fathers' education, and residence were not significant associated with occurrence of back pain among studied schoolchildren
( $P>0.05)$. However, it was revealed that gender, mothers' education, and parent's history of back pain had significant associated with occurrence of back pain among school children. Regarding sex, the present result showed that female students had more risk of suffering from back pain by five times than male students. This may be related to physiological differences between the two sexes. This result was in accordance with several studies showed that gender is a significant factor for development of back pain among school children. Girls were more likely to report back pain than boys of the same age $[6,14,16,33,43,44]$.

Concerning family history of back pain, the present result revealed that students with positive parents' history of back pain are four times more likely to suffer from back pain than students with negative parents' history of back pain This result was in line with $[14,36]$ reported a significant association between back pain in parents or the responsible guardian and back pain in schoolchildren. Also, similar to the results of [25] they reported that the probability of back pain occurrence in children increases 4.7 times if the children perceive an occurrence of parental back pain.

According to the present study, there was no significant relation between back pain and mean age of school children. This result was in agreement with $[36,43]$ they revealed that back pain was not significant associated with age of children and adolescents. On the contrary, other studies by [6, 7, 44] showed a significant association between age and frequency of occurrence of back pain in which a significant increase in prevalence as age increases. This difference may be related to variation in age group. Also, the present result showed that no significant relation between place of residence and back pain $(\mathrm{P}>0.05)$. This finding was supported by [40] who assessed characteristics of back pain in Polish youth aged 13-19. They showed no effect of the place of residence on the prevalence of spinal pain in youths. Similar to the results of [45] who found that residence had no significant relationship with occurrence of musculoskeletal pain in students in Tulkarm District.

Regarding relation between back pain and behavioral habits, the present result showed that physical exercise practice and frequency of practice weekly had no associated with back pain occurrence among school children $(\mathrm{P}>0.05)$. This finding was in line with $[46,36]$ they reported that there was no significant relation between physical or sports activities and back pain. On the contrary, another study conducted by [44] confirmed significant association between physical activity level and back pain. This difference in results may be due to different levels of practice and intensity of training between studies or different methods of analysis used in these studies. However, it was revealed that duration /day spent in sedentary activities during studying, watching television and using compute was associated with occurrence of back pain $(\mathrm{P}=0.000)$. Students who spent eight or more hours per day in sedentary activities had approximately three times more likely to suffer from back pain than those spent five hours or less per day. This result was in agreement with [38] they assessed musculoskeletal pain and school bag use 
among Ugandan pupils. They showed that there was a significant correlation between the time pupils spent sitting and the occurrence of back pain. Similarly to the result of [28] who stated that over half of students remain in a sitting position at least 8 hours per day in a sedentary activity, making it a risk factor for the occurrence of back pain. In contrast, a study conducted among adolescents aged 10-17 years by [44] who showed that the time spent doing sedentary activities did not present any relationship with lumbar pain. This difference may be related to various amounts of time spent in sedentary activities in other studies.

Relation between school bag characteristics and back pain: the present result showed that type of school bag and method of transportation to and from school had no associated with occurrence of back pain among studied students $(\mathrm{P}>0.05)$. This result was in agreement with [35, 45] who did not find an association between back pain and mode of transport of school supplies. Also, another study conducted among school children aged from 11 to 16 years by [14] they found no significant association between type of school bag carrying school materials and back pain.

However, the present finding showed that method of carrying school bag, duration of carriage, \% of school bag weight to student weight, feeling school bag heavy had significant associated with occurrence of back pain. Regarding method of carrying school bag, the present study showed that carrying school bag on one shoulder or by one hand increases the risk of suffering from back pain by about four times than students' carrying school bags on both shoulders. This finding was in accordance with the findings from review studies that showed carrying school bag on one shoulder, or by one hand causes asymmetry in muscle activity and encourages lateral spinal bending and might lead to changes in shoulder level and development of shoulder, neck and lower back pain even if the bag weight constitutes $10 \%$ of the child's weight [45, 47]. Similarly, a study conducted among Egyptian school girls aged from 6-14 years and found that way of carriage bag had associated with girls back pain. Likewise, a study conducted in Southern Brazil by [14] among school children aged from 11 to 16 years of age. They found association between the presence of back pain and the way of carrying school supplies. On the contrary, another study revealed no significant relationship between the method of carrying school bag and the prevalence of back pain [46]. This difference may be related to the differences in curriculum of school, method of travelling to and from school or weight of school bag in each of the different countries.

Regarding relationship between duration of carrying school bag and back pain, the present result showed that school children who are carrying school bags for $20-30$ minutes or more per day had more likely to suffer from back pain by about three times than those who are carrying school bags for $<10$ minutes. This findings was supported by the results of other studies [43, 45, 46] revealed that longer periods of time spent carrying a school bag each day influences cervical, shoulder and lumbar posture and could contribute to the musculoskeletal pain. Likewise, a study conducted by [38] revealed that the duration of time spent by the children carrying their school bags had a significant positive correlation with the occurrence of reported back pain. As regards perception of schoolbag weight in the present study, schoolchildren who reported that their school bags heavy were 2.4 times more likely to suffer from back pain than school children who were not having this feeling This result was in line with [35] that confirmed a significant association between reported weight of the backpack and pain.

The current result revealed a significant relationship between back pain and school bag weight, where the mean weight of school bag carried by school children complaining of back pain was significant higher $7.93+2.67 \mathrm{~kg}$ compared to $6.12+1.95 \mathrm{~kg}$ carried by schoolchildren not complaining of back pain. This result was in agreement with [10] who conducted study among Egyptian school girls showed a significant relationships between school bag associated pain and bag weight. In contrast, Papadopoulou et al. [30] found no significant relationship between back pain and schoolbag weight. This difference may be related to differences in school curriculum

The scientific community recognizes that the weight carried in bags by elementary and middle school students is a critical point and a risk factor for the onset of back pain in children and adolescents, and this symptom can last in the adulthood [42]. The weight of the school bag carried by the students varies greatly from one area to another according to curriculum [48]. In the present study, the mean weight of school bag carried by all school children was $7.46 \pm 2.6 \mathrm{~kg}$. This finding was in line with [49] who studied musculoskeletal effects of heavy backpacks in school children aged 11-14 years in India. They found that the total mean weight of the backpack was $6.75 \pm 0.99 \mathrm{~kg}$. In contrast, another study conducted by [43] among school children aged 12-14 years. They reported that the average load carried by students was $2.8 \mathrm{~kg}$. This difference may be related to differences in school curriculum or the type of books required in each of the different countries and culture differences.

Concerning school bag weight as a percentage of body weight $(\%$ of $\mathrm{BW})$, the present study showed the mean school bag weight as $\%$ of BW carried by students was $14.15 \% \pm$ 4.3. This finding was in line with [42] who evaluated the load carried by students in primary and secondary schools in Brazil. They found that average load carried by students was $13.8 \% \pm 3.5$. In contrast, another study conducted in Iran by [43] among students' found lower percentages 7.1\%. Other studies found higher percentages of body weight, a study conducted in Assiut City among elementary school children aged between 6 and 12 years by [39] showed that the mean schoolbag was $20.3 \% \pm 5.4$. Also, a study carried out in South India by [20] reported the mean schoolbag weight of elementary school children was $16.3 \%$ of their body weight. The difference may be related to socio-demographic and culture factors. 
According to the results of present study, there was significant relation between back pain and school bag weight as $\%$ of BW. School children who carrying school bags between $10.1 \%-15 \%$ and $>15 \%$ of their body weight were more likely to suffer from back pain complain by about 2.6 times and 6.1 times respectively than those carrying school bags $\leq 10 \%$ of their body weight. This result was supported by the majority of review studies indicated that schoolbag greater than the recommended weight $(10 \%$ of student body weight) for long period of time might affect the musculoskeletal alignment which will cause back pain, neck pain, and shoulder pain [43, 48]. Similar to the findings of $[20,45]$ they showed that there was a significant association between back pain and percentage of school bag weight. Likewise, Aundhakar et al. [34] showed that students carrying backpacks of more than $15 \%$ of their body weight had 4.34 times higher risk of pain when compared to students carrying $<10 \%$ of their body weight.

Regarding relationship between BMI and back pain, the present result revealed that mean of BMI was not associated with back pain. Similarly with [43] who reported that BMI was not associated with the occurrence of neck, shoulder and low back pain complaint. Also, the result was in line with [30] showed no association between back pain and BMI. On the contrary, a study conducted to assess prevalence of back pain among female school students aged 14 to 18 years in southern Brazil. They found BMI was associated with back pain [35]. The difference may be explained by difference in age group, gender, size of the sample, and different methods in measuring weight and height.

\section{Relation between postural habits and back pain}

Sitting posture for long-period increases pressure on the intervertebral discs, which leads to disc malnutrition, contribute to the development of general discomfort such as pain, fatigue, and a spinal degenerative process, and it may endanger the integrity of the musculoskeletal system $[19,36]$. The current result showed that there was a significant relationship between the occurrence of back pain and improper sitting posture for writing, using computer and sitting in classroom. Students who stayed in sitting posture for long periods throughout the day much of the time in an inappropriate posture (forward trunk flexion, lack of back and forearm support) had a higher percentage of back pain compared to students who adopted proper sitting posture. This finding was in accordance with [14] they reported significant association between back pain and sitting during writing and using the computer. Also, a study conducted among school adolescents in Brazil by [19] they revealed that students who usually sit with not recommended posture may be predisposed to higher levels of general discomfort. Likewise, Noll et al. [36] they found an association between back pain and postural variables including sitting posture when writing, using a computer, and sitting on a bench. Similar to [28] who studied back pain and postural habits of students in the public school in Teutônia. They found a significant relationship between the occurrence of back pain and inappropriate sitting posture for writing. Furthermore, Fonseca et al. [35] who showed in bivariate analysis students who adopted incorrect postures in class had a higher prevalence of pain compared with those students who adopted correct posture in the classroom.

According to the present result, there was significant relationship between the occurrence of back pain and posture for picking up objects from the floor. School children who reported picking up objects from the floor with improper posture (trunk flexion without bending the knees) had more occurrence of back pain compared with those who adopted a proper posture (bending the knees and keeping the back straight). This result was in accordance with [35] they showed that back pain was associated with incorrect posture when picking up objects from the ground.

Therefore, based on the findings, and taking into consideration that poor posture behaviors begin in childhood and adolescence and can cause back pain and structural postural problems of the spine. It is important in this stage of life to improve awareness about the importance of maintaining proper posture during school activities [35].

\section{Conclusion}

The occurrence of back pain in school children of the studied sample was high (74\%) and about one fourth (24.3\%) of them reported that the pain prevented them from performing daily activities and $71.3 \%$ did not take any action for alleviating back pain. Among school children with back pain, 51.3\% had reported moderate pain and the most affected area by pain was shoulder followed by neck. It was associated with sex, parents' family history of back pain, duration of sedentary activities/ day, improper sitting posture for writing, in the classroom and using computer, weight of school bag, $\%$ of body weight, method \& duration of carrying school bag.

\section{Recommendations}

a The need for developing and implementing of educational and preventative programs in schools about proper postures during daily activities and guidelines for schoolbag usage.

b The Ministry of Education has a role in educating the community including the students, teachers and parents about potential health hazards produced by carrying heavy school bags, improper postures during sedentary activities for long period.

c Limiting school bag weight to less than $10 \%$ of student body weight.

d This study highlighted that further in-depth analytic study designs are needed and recommended to determine whether the observed associations in this study, is actually a causal valid association? 


\section{References}

[1] Rajan, P., \& Koti, A. (2013). Ergonomic assessment and musculoskeletal health of the Underprivileged school children in Pune, India. Health Promotion Perspectives, 3 (1), 36-44.

[2] Weiguang, Y., Xiaodan, M., Chenling, L., Fuzhi, A., \& Qing, C. (2011). A cross-sectional survey of non-specific low back pain among school children in China. Spine; In Press.

[3] Ramprasad, M., Alias, J., Raghuvee, r A. (2009). Effect of backpack weight on postural angles in preadolescent children. Indian Pediatrics; 47: 572-573.

[4] Wirth, B., Humphreys, B. K. (2015). Pain characteristics of adolescent spinal pain. BMC Pediatr; 15: 42.

[5] Adeyemi, A. J. Rohani, J. M. \& Abdul Rani, M. R. (2013). Multifactorial model based on self-reported back pain among Nigerian schoolchildren and the associated risk factors. World Applied Sciences Journal, 21 (6): 812-818.

[6] Kedra, A., \& Czaprowski, D. (2013). Epidemiology of back pain in children and youth aged 10-19 from the area of the Southeast of Poland. BioMed Research International; Volume 2013: $1-6$

[7] Mohammad, W. S., \& El-Sais, W. M. (2013). Prevalence of non- specific self-reported back pain among adolescents at Hail territory -KSA. Journal of Asian Scientific Research; 3 (10): 1036-1045.

[8] Pellisé, F., Balagué, F., Rajmil, L., Cedraschi, C. Aguirre, M., Fontecha, C. G., Pasarín, M., Ferrer, M. (2009). Prevalence of low back pain and its effect on health-related quality of life in adolescents. Archives of Pediatrics and Adolescent Medicine; 163 (1): 65-71.

[9] Drozda, K., Lewandowski, J., Górski, P. (2011). Back pain in lower and upper secondary school pupils living in urban areas of Poland. Ortopedia Traumatologia Rehabilitacja; 13, (5): 489-503.

[10] Ibrahim, A. H., (2012). Incidence of Back Pain in Egyptian School Girls: Effect of school bag weight and carrying way. World Applied Sciences Journal; 17 (11): 1526-1534.

[11] Sato, T., Ito, T., Hirano, T., Morita, O., Kikuchi, R., Endo, N., Tanabe, N. (2011). Low back pain in childhood and adolescence: assessment of sports activities. Eur Spine J; 20 (1): 94-99.

[12] Vitta, A., Martinez, M. G., Piza, N. T. Simeão, S., Ferreira, N. P. (2011). Prevalence of lower back pain and associated factors in students. Cad. Saúde Pública (Rio de Janeiro, Brasil; 27 ( 8): 1520-1528.

[13] Graup, S., Santos, S. G., Moro, A. R. (2010). Descriptive study of sagittal lumbar spine changes in students of federal educational system Florianopolis. Rev Bras Ortop; 45 (5): 453-9.

[14] Noll, M., Candotti, C. T., Rosa, B. N., Loss, J. F. (2016 ). Back pain prevalence and associated factors in children and adolescents: an epidemiological population study. Rev Saude Publica; 50: 31.
[15] Cynthia, H., \& Burstein, G. R. (2016). Adolescent physical and social development. In: Nelson Textbook of Pediatrics. First South Asia Edition. Elsevier; p. 926-931.

[16] Rai, A.,\& Agarawal, S. (2013). Back Problems Due To Heavy Backpacks in School Children. IOSR Journal of Humanities and Social Science; 3 (10), 109-116.

[17] Arghavani, F., Zamanian, Z., Ghanbary, A., \& Hassanzadeh, J. ( 2014). Investigation of the relationship between carrying school bags (Handbags and Backpacks) and the Prevalence of musculoskeletal pains among 12-15 year old students in Shiraz. Pakistan Journal of Biological Sciences; 17 (4): 550-554.

[18] Pereira, D. L., Castro, S. S., Bertoncello, D., Dami, R., \& Walsh, I. A. (2013). Relationship of musculoskeletal pain with physical and functional variables and with postural changes in school children from 6 to 12 years of age. Braz J Phys Ther, 17 (4): 392-400.

[19] Meziat Filho, N., Coutinho, E. S., \& Azevedoe Silva, G. (2015). Association between home posture habits and low back pain in high school adolescents. Eur Spine J; 24: 425433.

[20] Balamurugan, J. (2014). School Bags and musculoskeletal pain among elementary school children in Chennai City. International journal of Medical Science and Clinical Invention; 1 (6): 302-309.

[21] American Academy of Pediatrics. (2016). Role of the school nurse in providing school health services (Policy Statement). Pediatrics, originally published online May 23, 2016.

[22] National Association of School Nurses. (2016). The role of the 21st century school nurse (Position Statement). Silver Spring, MD: Author.

[23] Mclaughlin, K. \& Teti, B. (2011). Back Pain in Children: A Holistic Approach to Diagnosis and Management. Journal of Pediatric Health Care; 25 (5): 284-293.

[24] Munaz, C., Conesa, A., \& Meca, J. (2013). Prevalence of low back pain in children and adolescents. BMC Pediatrics; 13: 14.

[25] Trigueiro, M. J., Massada, L.,\& Garganta, R. Back pain in Portuguese schoolchildren: prevalence and risk factors. Eur $J$ Public Health; 23: 499-503.

[26] Noll, M., Vieira, A., Darski, C., Candotti, C. T. Back School developed in Brazil. (2014). Review about the intervention methodology, assessment tools and results. Rev Bras Reumatol; 54: 51-58.

[27] Hundekari, J., Chilwant, K., Vedpathak, S., Wadde, S. (2013). Does alteration in backpack load affects posture of school children?. Group; 2: 10-20.

[28] Noll, M., Candotti, C. T., Nichele, B., Cristina, M, Schoenell, W, Tiggemann C. L. (2013). Back pain and the postural and behavioral habits of students in the municipal school network of Teutônia, Rio Grande do Sul. J Hum Growth Dev; 23: 129-135.

[29] Qidwai, W., Ishaque, S., Shah, S., Rahim, M. (2010). Adolescent lifestyle and behavior: A survey from a developing country. PloS one; 5 (9): e12914.

[30] Papadopoulou, D. 1., Malliou, P. 1., Kofotolis, N., Emmanouilidou, M. I. Kellis, E. (2014). The association between grade, gender, physical activity, and back pain among children carrying schoolbags. Arch Exerc Health Dis 4 (1): 234-242. 
[31] Von Baeyer, C. L. (2009). Numerical rating scale for selfreport of pain intensity in children and adolescents: Recent progress and further questions. Eur J Pain; 13: 1005-7.

[32] Noll, M., Candotti, C. T; Vieira, A., Loss, J. F. (2013). Back Pain and Body Posture Evaluation Instrument (BackPEI): Development, Content Validation and Reproducibility. Int $J$ Public Health; 58: 565-572.

[33] Sirsat, J., Rehman, Z., Rajan, R., Kumar, S., Mirghani, A., AlQatrani, R., Khan, F. (2014). Prevalence of back pain among high school students: A cross-sectional study in Dubai, United Arab Emirates. Gulf Medial Journal, 3 (S2): S16-S23.

[34] Aundhaka, r C. D., Bahatkar, K. U., Padiyar, M. S., Jeswani, D. H., Colaco, S. (2015). Back pain in children associated with backpacks. Indian J Pain; 29: 29-31.

[35] Fonseca, C. D., Candotti, C. T., Noll, M., Dos Santos, A. C, Corso, C. O. Prevalence of back pain among high school students in a municipality in southern Brazil. Fisioter Mov, 29 (1): $137-46$

[36] Noll, M., de Avelar, I. S, Lehnen, G. C., Vieira, M. F. (2016). Back Pain Prevalence and its associated factors in Brazilian Athletes from public high schools: A cross-Sectional study. PLOS ONE 11 (3): 1-16.

[37] Ibrahim, A. A., Jayavel, A., Suleiman, S. K., Nuhu, J. M. (2015). Influence of schoolbag use on musculoskeletal discomforts among university students. International Journal of Health Sciences \& Research5 Issue: 5; 222-231.

[38] Mwaka, E. S., Munabi, I. G., Buwembo, W., Kukkiriza, J., \& Ochieng, J. (2014). Musculoskeletal pain and school bag use: a cross-sectional study among Ugandan pupils. BMC Research Notes 7: 222.

[39] El Magrabi, N. M., Mahmoud, S. R., and Yousef, Y. E. (2015). Awareness of parents about school backpack and its related musculoskeletal disorders in Assiut City. IOSR Journal of Nursing and Health Science, 4, (6): 05-11.

[40] Lewandowski, J., \& Łukaszewska, K. (2014). Characteristics of back pain in Polish youth depending on place of residence. Ann Agric Environ Med.; 21 (3): 644-648.

[41] Kjaer, P., Wedderkopp, N., Korsholm, L., Leboeuf-Yde, C.
(2011). Prevalence and consequence of back pain from childhood to adolescence. BMC Musculoskelet Disord 12 (1): 98 .

[42] De Paula, A. J. F., Silva, J. C. P., Silva, J. C. R. P. (2015). The influence of load imposed by the backpack school in children and teens in Brazil. Science Direct, Procedia Manufacturing; 3 (2015): 5350 - 5357.

[43] Dianat, I., Sorkhi, N., Pourhossein, A., Alipour, A., \& Asghari, M. (2014). Neck, shoulder and low back pain in secondary schoolchildren in relation to schoolbag carriage: Should the recommended weight limits be gender-specific. Applied Ergonomics, 31; 45: 437-442.

[44] Graup S., Bergmann, M. L., Bergmann, G. G. (2014). Prevalence of nonspecific lumbar pain and associated factors among adolescents in Uruguaiana, state of Rio Grande do Sulem. Rev Bras Ortop; 49: 661-667.

[45] AL-Qato, A. K. \& Khalil, I. (2012). The Influence of Backpacks on Students backs: A Cross-Sectional Study of Schools in Tulkarm District. Degree of Master of Public Health, Faculty of Graduate Studies, An-Najah National University, Nablus, Palestine.

[46] Mohamed S. A. (2013). Incompatibility between Studentsec Body measurements and school chairs. World Applied Sciences Journal; 21: 689-

[47] Drzał-Grabiec, J., Snela, S., Rachwał, M., Podgórska, J., Rykała, J. (2015). Effects of carrying a backpack in an asymmetrical manner on the asymmetries of trunk and parameters defining lateral flexion of the spine. Human Factors: The Journal of the Human Factors and Ergonomics Society; 1 (57): 218-26.

[48] Sahib, M. A. (2016). The Effects of schoolbags on the health of students Karbala J. Med. 9 (1), 2301-2315.

[49] Patil, M. A., Sumana, S., Shagale, N. (2016). Musculoskeletal effects of heavy backpacks in school children of 11-14 years. Int J Pediatr Res. 3 (6): 421-426.

[50] Newcombe, R. G. (2012). Confidence intervals for proportions and related measures of effect size. Chapman \& Hall/CRC Biostatistics Series, Taylor \& Francis, Boca Raton, FL. ISBN: 978-4-4398-1278-5. 